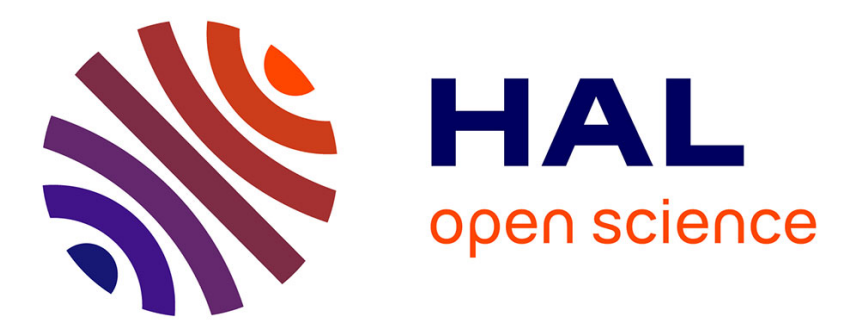

\title{
Study of HTS Magnetic Coupler Using Analytical and Numerical Computations
}

Lamia Belguerras, Larbi Hadjout, Smail Mezani, Thierry Lubin, Abderrezak Rezzoug

\section{- To cite this version: \\ Lamia Belguerras, Larbi Hadjout, Smail Mezani, Thierry Lubin, Abderrezak Rezzoug. Study of HTS Magnetic Coupler Using Analytical and Numerical Computations. IEEE Transactions on Applied Superconductivity, 2014, 14 p. 10.1109/TASC.2014.2326923 . hal-01011510}

\author{
HAL Id: hal-01011510 \\ https://hal.science/hal-01011510
}

Submitted on 24 Jun 2014

HAL is a multi-disciplinary open access archive for the deposit and dissemination of scientific research documents, whether they are published or not. The documents may come from teaching and research institutions in France or abroad, or from public or private research centers.
L'archive ouverte pluridisciplinaire HAL, est destinée au dépôt et à la diffusion de documents scientifiques de niveau recherche, publiés ou non, émanant des établissements d'enseignement et de recherche français ou étrangers, des laboratoires publics ou privés. 


\title{
Study of HTS Magnetic Coupler Using Analytical and Numerical Computations
}

\author{
Lamia Belguerras, Larbi Hadjout, Smail Mezani, Thierry Lubin, and Abderrezak Rezzoug
}

\begin{abstract}
In this paper, we propose a method to calculate the magnetic field in Flux Concentration Superconducting Magnetic Coupling (FCSMC) with rectangular permanent magnets (PMs). The inner rotor is composed of rectangular PMs and the external one is made of High Temperature Superconducting (HTS) coils supplied by DC current. Firstly, an exact 2-dimensional analytical computation is developed in polar coordinates for calculating the magnetic field distribution in FCSMC with sector PMs having the same volume as the rectangular ones. The model is validated by finite element computations. The analytical model is then used to predict the performances of FCSMC. The electric loadability of the FCSMC is determined by considering the dependence of the critical current vs. the flux density distribution. A parametric study showed that the analytical model can predict the torque with a reasonable precision. Therefore, this model can usefully be used for optimization purposes where reductions in computation time are needed.
\end{abstract}

Index Terms - Analytical solution, BSCCO tape, flux concentration, high temperature superconductors, magnetic coupler, permanent magnet.

\section{INTRODUCTION}

$\mathrm{M}$ agnetic Couplings (or couplers) (MCs) are widely used in industry to transmit a torque from a prime mover to its load without contact through a separation wall which can be air, vacuum, fluid or other media. Such contactless torque transmission devices have found wide applications in nuclear environments, vibration isolation, compressors, blowers, vacuum pumps [1]. There are three types of MCs: Eddy current, Hysteresis and Synchronous, each of which may be of Concentric or Axial topology.

The use of High Temperature Superconductors (HTS) in electromagnetic devices is currently an important subject of research worldwide. Indeed, these materials can be efficiently used for developing high magnetic flux density in machines with large air gap as couplers and gears [2, 3].

Manuscript received September 30, 2013; revised March 31, 2014; accepted May 12, 2014.

L. Belguerras, S. Mezani, T. Lubin and A. Rezzoug are with the Groupe de Recherche en Electrotechnique et Electronique de Nancy (GREEN), University of Lorraine, 54506 Vandoeuvre les Nancy, France (e-mail: lamia.belguerras@univ-lorraine.fr, $\quad$ smail.mezani@univ-lorraine.fr; thierry.lubin@univ-lorraine.fr; abderrezak.rezzoug@univ-lorraine.fr).

L. Hadjout is with USTHB, Laboratoire LSEI, 16111, El-Allia, Bab Ezzouar, Algeria (e-mail: lhadjout@yahoo.fr).
In the same context, a flux concentration (or flux focusing) concept is an effective solution since the machine produces more torque compared to the ones with surface mounted PMs [4].

The aim of this paper is to use HTS and PMs to transmit high torque from a cold environment to a warm environment using a superconducting magnetic coupler. For example, the torque produced by a HTS motor can be transmitted to its load via the HTS magnetic coupler of Fig.1.a. This may constitutes an alternative solution to torque tubes. A $3 \mathrm{D}$ view of the studied flux concentration coupler is shown in Fig.1.b.

Obviously, this doesn't constitute the sole application of a magnetic coupler. Many industrial processes (i.e. nuclear, chemical, pharmaceutical and food industries) need hermetic isolation between the prime mover and a follower connected to the process.

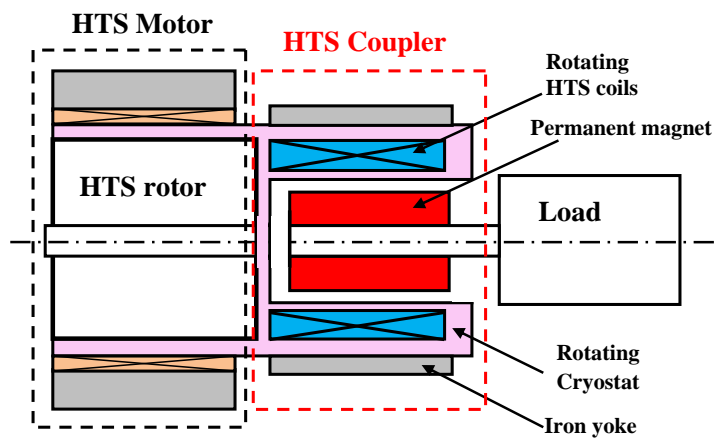

(a)

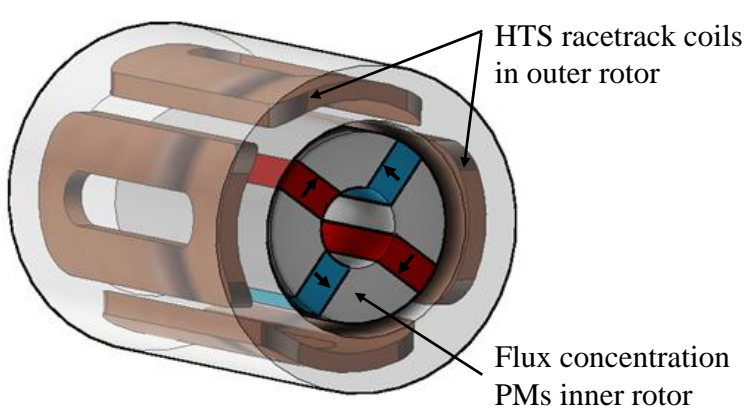

(b)

Fig. 1. (a) Schematic diagram showing the use of a superconducting magnetic coupler, (b) 3D view of the studied flux focusing coupler. 
The proposed HTS coupler (or a wholly HTS coupler whose both inner and outer rotors are superconducting) may be the unique solution if large distance between the two rotors is required (several centimeters). In fact, superconductors are the only materials which can create enough magnetic field to transmit a torque without contact, and within a reasonable coupler volume, throw a thick wall.

Usually, the magnets of flux concentration permanent magnets rotor are rectangular (as in Fig.1.b). The distribution of magnetic field can be calculated by dividing the rectangular magnets into a finite number of radial slices. However, this will drastically increase the number of sub-domains and penalizes the computation time. Another solution consists of using conformal mapping to handle the non radial areas of slot domains [5].

In this study, the rectangular magnets are replaced by sector ones having the same volume so the magnetic field distribution can be calculated by using analytical method. In this technique, polar coordinates are used and Maxwell's equations are solved by separation of variables in low permeability sub-domains (air regions, magnets, windings) [6, 7, 8, 9]. In particular, flux concentration switched PMs machines have been studied in [10].

The first part of this paper introduces the sector PMs FCSMC and the analytical calculation of the magnetic field. The results are validated by finite element (FE) computation.

In the second part, we propose a method to calculate the critical current in the superconducting coil by taking into account the HTS tape characteristics and the flux density on the HTS wire. This flux density is calculated by the analytical and the numerical techniques.

In the last part, we will analyze the capability of the developed analytical model in predicting critical current of HTS coil and rectangular magnets FCSMC performances. A discussion on the obtained results ends the paper.

\section{STUDIED SUPERCONDUCTING MAGNETIC COUPLER}

The considered coupler is coaxial (or concentric); it has one rotor inside another rotor. The inner rotor consists of different pieces of iron and permanent magnets that are fixed jointly on a non-ferromagnetic shaft; each magnet is magnetized in a reverse direction of its neighboring ones. The outer rotor is composed of a series of HTS coils separated by pieces of glass fiber. The coils are cooled inside a non magnetic cryostat (stainless steel) at 30K (Fig.2).

The geometrical parameters of prototype FCSMC to be investigated (Fig.3) are

- The inner radius of the inner rotor $R_{1}$

- The outer radius of the inner rotor $R_{2}$

- The inner radius of the HTS winding $\mathrm{R}_{3}$

- The outer radius of the HTS winding $R_{4}$

- The inner radius of outer rotor yoke $R_{5}$

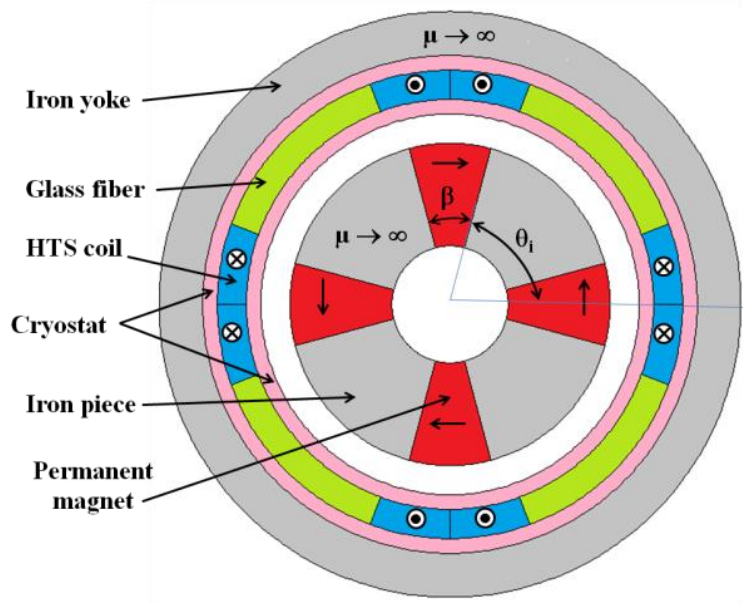

Fig. 2. 2D geometry of the studied superconducting magnetic coupler $(\mathrm{p}=2)$

The inner rotor consists of $2 p$ ( $p$ is the number of polepairs) sector PMs. The angular position of the $i$-th PM is defined (Fig. 2) by

$$
\theta_{i}=-\frac{\beta}{2}+\frac{i \pi}{p} \quad \text { with } 1 \leq i \leq 2 p
$$

Where $\beta$ is the PM opening angle.

\section{PROBLEM FORMULATION AND ASSUMPTIONS}

A 2D analytical model is developed where a magnetic vector potential formulation is used in polar coordinates. The relative permeability is considered infinite for the ferromagnetic parts and is equal to 1 for the PMs and air regions. The inner rotor is in a fixed position for all the calculations.

\section{A. Source Terms}

The permanent magnets buried into the rotor of the machine are tangentially magnetized. The magnetization direction is alternated from one magnet to another. Hence, the magnetization vector of the $\mathrm{i}^{\text {th }}$ permanent magnet regions is

$$
\vec{M}=(-1)^{i} \frac{B_{r}}{\mu_{0}} \overrightarrow{e_{\theta}}
$$

where $B_{r}$ is the remanent flux density of the magnet.

The HTS coils in the outer rotor are supplied by direct current (Fig. 4). The Fourier series expansion of the current density $J$ of the HTS winding is given by

$$
\begin{gathered}
J(\theta)=\sum_{n=1}^{\infty} J_{n} \cos (n \theta-\varphi), \text { n odd } \\
J_{n}=\frac{4}{n \pi} J_{0} \sin \left(\frac{\mathrm{n} \alpha_{w} \pi}{2}\right), \quad 0<\alpha_{w}<1
\end{gathered}
$$

Where $J_{0}$ is the dc current density in the superconductor and $\varphi$ the load angle (angle between the magnetic fields created by the HTS rotor and the PM rotor). $\alpha_{w}$ is the ratio between the HTS coil cross section width $\left(R_{3} \alpha_{w} \pi / 2 p\right)$ and half of the pole pitch $\left(\mathrm{R}_{3} \pi / 2 \mathrm{p}\right)$. 


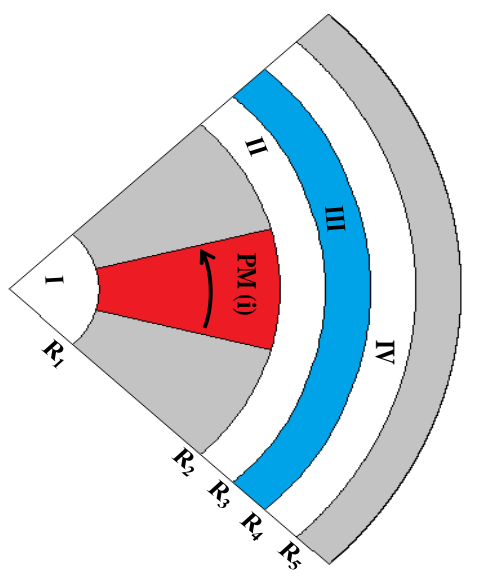

Fig. 3. Studied sub-domains

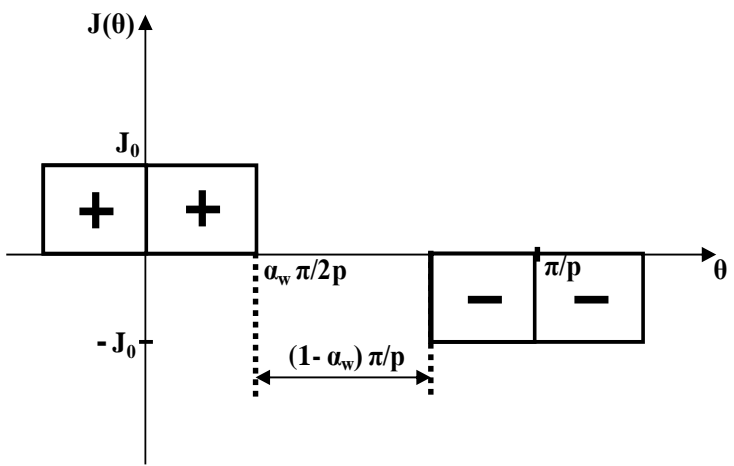

Fig. 4. Current density distribution in the HTS windings along the $\theta$ direction $(\varphi=0)$

B. Analytical expressions of the magnetic field in the different subdomains

The studied structure is divided into a shaft (domain I), airgap (domain II), HTS winding (domain III), outer cryostat wall (domain IV) and permanent magnet regions (domains $i$ ), Fig. 3. Notice that the air gap includes the inner wall of the cryostat (non magnetic) and a mechanical clearance to allow the rotation.

In order to simplify the analytical expressions in the different sub-domains, we adopt the following notations

$$
\begin{aligned}
& P_{z}(a, b)=\left(\frac{a}{b}\right)^{z}+\left(\frac{b}{a}\right)^{z} \\
& E_{z}(a, b)=\left(\frac{a}{b}\right)^{z}-\left(\frac{b}{a}\right)^{z}
\end{aligned}
$$

In polar coordinates, for the i-th permanent magnet subdomain region and in the HTS winding domain, Poisson's equations apply

$$
\begin{gathered}
\Delta A_{i}=-(-1)^{i} \frac{B_{r}}{r} \\
\Delta A_{\text {III }}=-\mu_{0} J
\end{gathered}
$$

For the sub-domains I, II and IV, Laplace's equations have to be solved

$$
\begin{aligned}
\Delta A_{I} & =0 \\
\Delta A_{I I} & =0 \\
\Delta A_{I V} & =0
\end{aligned}
$$

\section{Boundary conditions}

The boundary conditions for the $i$-th PM domain (Fig. 5) are

$$
\left.\frac{\partial A_{i}}{\partial \theta}\right|_{\theta=\theta_{i}}=0 \text { and }\left.\frac{\partial A_{i}}{\partial \theta}\right|_{\theta=\theta_{i}+\beta}=0
$$

The continuity conditions of the magnetic vector potential between the $i$-th PM and sub-domains I, II are

$$
\begin{aligned}
& A_{i}\left(R_{1}, \theta\right)=A_{I}\left(R_{1}, \theta\right) \\
& A_{i}\left(R_{2}, \theta\right)=A_{I I}\left(R_{2}, \theta\right)
\end{aligned}
$$

The boundary condition for the region III is given by

$$
\left.\frac{\partial A_{I I}}{\partial r}\right|_{r=R_{3}}=\left.\frac{\partial A_{I I I}}{\partial r}\right|_{r=R_{3}}
$$

The boundary conditions for the region IV are given by

$\left.\frac{\partial A_{I V}}{\partial r}\right|_{r=R_{4}}=\left.\frac{\partial A_{I I I}}{\partial r}\right|_{r=R_{4}}$

$\left.\frac{\partial A_{I V}}{\partial r}\right|_{r=R_{5}}=0$

The continuity conditions of the magnetic vector potential between the sub-domain III and sub-domains II, IV are

$$
\begin{aligned}
& A_{I I I}\left(R_{3}, \theta\right)=A_{I I}\left(R_{3}, \theta\right) \\
& A_{I I I}\left(R_{4}, \theta\right)=A_{I V}\left(R_{4}, \theta\right)
\end{aligned}
$$

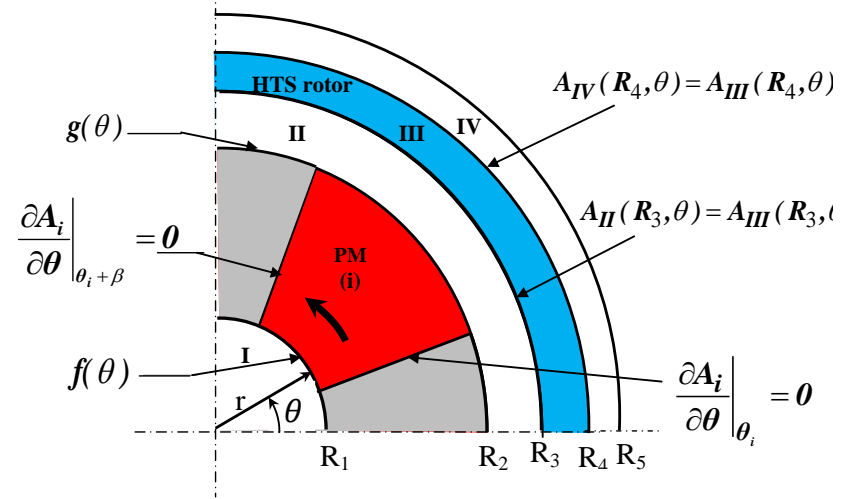

Fig. 5. Boundary conditions 
The continuity of the tangential magnetic field at the interface between the permanent magnet and the shaft, can be written as

$$
\left.\frac{\partial A_{I}}{\partial r}\right|_{r=R_{1}}=f(\theta)
$$

with

$$
f(\theta)=\left\{\begin{array}{lc}
\left.\frac{\partial A_{i}}{\partial r}\right|_{\mathrm{r}=\mathrm{R}_{1}}+(-1)^{i} B_{\mathrm{r}} \quad \text { if } \theta \in\left[\theta_{\mathrm{i}}, \theta_{i}+\beta\right] \\
0 \quad \text { elsewhere }
\end{array}\right.
$$

The continuity of the tangential magnetic field at the interface between the permanent magnet and the air gap can be written as

$$
\left.\frac{\partial A_{I I}}{\partial r}\right|_{r=R_{2}}=g(\theta)
$$

with

$$
g(\theta)=\left\{\begin{array}{lc}
\left.\frac{\partial A_{i}}{\partial r}\right|_{\mathrm{r}=\mathrm{R}_{2}}+(-1)^{i} B_{\mathrm{r}} \text { if } \theta \in\left[\theta_{\mathrm{i}}, \theta_{i}+\beta\right] \\
0 \quad \text { elsewhere }
\end{array}\right.
$$

\section{ANALYTICAL SOLUTIONS}

To solve the partial differential equations, the method of separation of variables is used in cylindrical coordinates.

\section{A. General Solution of Posson's equation in the $i$-th PMs sub-} domain (region i)

In the $\mathrm{i}^{\text {th }} \mathrm{PM}$ sub-domain, the problem to solve is

$$
\frac{\partial^{2} A_{i}}{\partial r^{2}}+\frac{1}{r} \frac{\partial A_{i}}{\partial r}+\frac{1}{r^{2}} \frac{\partial^{2} A_{i}}{\partial \theta^{2}}=-(-1)^{i} \frac{B_{r}}{r} \quad\left\{\begin{array}{l}
R_{1} \leq r \leq R_{2} \\
\theta_{i} \leq \theta \leq \theta_{i}+\beta
\end{array}\right.
$$

The general solution of (24) can be written as

$$
\begin{aligned}
& A_{i}(r, \theta)=-r(-1)^{i} B_{r}+A_{0}^{i}+B_{0}^{i} \ln r \\
& +\sum_{k=1}^{\infty}\left(A_{k}^{i} \frac{E_{k \pi / \beta}\left(r, R_{2}\right)}{E_{k \pi / \beta}\left(R_{1}, R_{2}\right)}-B_{k}^{i} \frac{E_{k \pi / \beta}\left(r, R_{1}\right)}{E_{k \pi / \beta}\left(R_{1}, R_{2}\right)}\right) \cdot \cos \left(\frac{k \pi}{\beta}\left(\theta-\theta_{i}\right)\right.
\end{aligned}
$$

where $\mathrm{k}$ is a positive integer, $E_{k \pi / \beta}\left(r, R_{2}\right)$ is given by (6).

The constants $A_{0}^{i}, B_{0}^{i}, A_{k}^{i}$ and $B_{k}^{i}$ are determined using a Fourier series expansion of shaft and air-gap vector potentials $A_{I}\left(R_{1}, \theta\right), A_{I I}\left(R_{2}, \theta\right)$ over the PMs region interval $\left[\theta_{i}, \theta_{i}+\beta\right]$. They are given by

$$
A_{0}^{i}+B_{0}^{i} \ln R_{1}=\frac{1}{\beta} \int_{\theta_{i}}^{\theta_{i}+\beta}\left(R_{1}(-1)^{i} B_{r}+A_{I}\left(R_{1}, \theta\right)\right) d \theta
$$

$A_{0}^{i}+B_{0}^{i} \ln R_{2}=\frac{1}{\beta} \int_{\theta_{i}}^{\theta_{i}+\beta}\left(R_{2}(-1)^{i} B_{r}+A_{I I}\left(R_{2}, \theta\right)\right) d \theta$

$A_{k}^{i}=\frac{2}{\beta} \int_{\theta_{i}}^{\theta_{i}+\beta}\left(R_{1}(-1)^{i} B_{r}+A_{I}\left(R_{1}, \theta\right)\right) \cos \left(\frac{k \pi}{\beta}\left(\theta-\theta_{i}\right)\right) d \theta$

$B_{k}^{i}=\frac{2}{\beta} \int_{\theta_{i}}^{\theta_{i}+\beta}\left(R_{2}(-1)^{i} B_{r}+A_{I I}\left(R_{2}, \theta\right)\right) \cos \left(\frac{k \pi}{\beta}\left(\theta-\theta_{i}\right)\right) d \theta$

B. General solution of Laplace's equation in the shaft subdomain (region I)

The shaft sub-domain and its associated boundary conditions are shown in Fig. 5. The equation to solve is

$\frac{\partial^{2} A_{I}}{\partial r^{2}}+\frac{1}{r} \frac{\partial A_{I}}{\partial r}+\frac{1}{r^{2}} \frac{\partial^{2} A_{I}}{\partial \theta^{2}}=0 \quad$ for $\left\{\begin{array}{l}0 \leq r \leq R_{1} \\ 0 \leq \theta \leq 2 \pi\end{array}\right.$

By taking into account the boundary condition (20), the general solution of the magnetic vector potential in the shaft can be written as

$$
A_{I}(r, \theta)=\sum_{n=1}^{\infty} \frac{R_{1}}{n}\left(\frac{r}{R_{1}}\right)^{n}\left(A_{n}^{I} \cos (n \theta)+B_{n}^{I} \sin (n \theta)\right)
$$

Where $n$ is a positive integer, the coefficients $A_{n}^{I}$ and $B_{n}^{I}$ are determined by using a Fourier series expansions of $f(\theta)$ over the interval $[0,2 \pi]$.

$$
\begin{aligned}
& A_{n}^{I}=\frac{2}{2 \pi} \int_{0}^{2 \pi} f(\theta) \cos (n \theta) d \theta \\
& B_{n}^{I}=\frac{2}{2 \pi} \int_{0}^{2 \pi} f(\theta) \sin (n \theta) d \theta
\end{aligned}
$$

\section{General solution of Laplace's equation in the air gap (region II)}

In the air-gap sub-domain, the problem to solve is

$$
\frac{\partial^{2} A_{I I}}{\partial r^{2}}+\frac{1}{r} \frac{\partial A_{I I}}{\partial r}+\frac{1}{r^{2}} \frac{\partial^{2} A_{I I}}{\partial \theta^{2}}=0 \text { for }\left\{\begin{array}{l}
R_{2} \leq r \leq R_{3} \\
0 \leq \theta \leq 2 \pi
\end{array}\right.
$$

According to the boundary conditions (15) and (22), the general solution of the magnetic vector potential in the air-gap sub-domain can be written as

$$
\begin{aligned}
& A_{I I}(r, \theta)= \\
& +\sum_{n=1}^{\infty}\left(A_{n}^{I I} \frac{R_{2}}{n} \frac{\mathrm{P}_{n}\left(r, R_{3}\right)}{\mathrm{E}_{n}\left(R_{2}, R_{3}\right)}+B_{n}^{I I} \frac{R_{3}}{n} \frac{\mathrm{P}_{n}\left(r, R_{2}\right)}{\mathrm{E}_{n}\left(R_{3}, R_{2}\right)}\right) \cos (n \theta) \\
& +\sum_{n=1}^{\infty}\left(C_{n}^{I I} \frac{R_{2}}{n} \frac{\mathrm{P}_{n}\left(r, R_{3}\right)}{\mathrm{E}_{n}\left(R_{2}, R_{3}\right)}+D_{n}^{I I} \frac{R_{2}}{n} \frac{\mathrm{P}_{n}\left(r, R_{2}\right)}{\mathrm{E}_{n}\left(R_{3}, R_{2}\right)}\right) \sin (n \theta)
\end{aligned}
$$


Where $n$ is a positive integer, $P_{n}\left(r, R_{3}\right)$ and $E_{n}\left(R_{2}, R_{3}\right)$ are defined by (5) and (6). The coefficients $A_{n}^{I I}, B_{n}^{I I}, C_{n}^{I I}$ and $D_{n}^{I I}$ are determined using a Fourier series expansions of $\left.\frac{\partial A_{I I I}}{\partial r}\right|_{\mathrm{r}=\mathrm{R}_{3}}$ and $g(\theta)$ over the air-gap interval $[0,2 \pi]$.

$$
\begin{aligned}
& A_{n}^{I I}=\frac{2}{2 \pi} \int_{0}^{2 \pi} g(\theta) \cos (n \theta) d \theta \\
& B_{n}^{I I}=\left.\frac{2}{2 \pi} \int_{0}^{2 \pi} \frac{\partial A_{I I I}}{\partial r}\right|_{r=R_{3}} \cos (n \theta) d \theta \\
& C_{n}^{I I}=\frac{2}{2 \pi} \int_{0}^{2 \pi} g(\theta) \sin (n \theta) d \theta \\
& D_{n}^{I I}=\left.\frac{2}{2 \pi} \int_{0}^{2 \pi} \frac{\partial A_{I I I}}{\partial r}\right|_{r=R_{3}} \sin (n \theta) d \theta
\end{aligned}
$$

D. General Solution of Poisson's equation in the HTS winding sub-domain (region III)

The problem to solve in the HTS winding region is given by the following equation

$$
\frac{\partial^{2} A_{I I I}}{\partial r^{2}}+\frac{1}{r} \frac{\partial A_{I I I}}{\partial r}+\frac{1}{r^{2}} \frac{\partial^{2} A_{I I I}}{\partial \theta^{2}}=-\mu_{0} J(\theta) \text { for }\left\{\begin{array}{l}
R_{3} \leq r \leq R_{4} \\
0 \leq \theta \leq 2 \pi
\end{array}\right.
$$

By taking into account the boundary conditions (18) and (19), the general solution for the magnetic vector potential is

$$
\begin{aligned}
& A_{I I I}(r, \theta)= \\
& +\sum_{n=1}^{\infty}\left(A_{n}^{I I I} \frac{E_{n}\left(r, R_{4}\right)}{\mathrm{E}_{n}\left(R_{3}, R_{4}\right)}+B_{n}^{I I} \frac{E_{n}\left(r, R_{3}\right)}{\mathrm{E}_{n}\left(R_{4}, R_{3}\right)}+\psi_{n}(r) \cos (\mathrm{n} \varphi)\right) \cos (n \theta) \\
& +\sum_{n=1}^{\infty}\left(C_{n}^{I I I} \frac{E_{n}\left(r, R_{4}\right)}{\mathrm{E}_{n}\left(R_{3}, R_{4}\right)}+D_{n}^{I I} \frac{E_{n}\left(r, R_{3}\right)}{\mathrm{E}_{n}\left(R_{4}, R_{3}\right)}+\psi_{n}(r) \sin (\mathrm{n} \varphi)\right) \sin (n \theta)
\end{aligned}
$$

With

$$
\begin{aligned}
\psi_{n}(r) & =\frac{E_{n}\left(r, R_{4}\right)}{\mathrm{E}_{n}\left(R_{4}, R_{3}\right)}\left[\left(\frac{R_{3}}{R_{4}}\right)^{n} X_{n}\left(R_{4}\right)-X_{n}\left(R_{3}\right)\right] \\
& +\frac{E_{n}\left(r, R_{4}\right)}{\mathrm{E}_{n}\left(R_{4}, R_{3}\right)}\left[\left(\frac{R_{4}}{R_{3}}\right)^{n} X_{n}\left(R_{3}\right)-X_{n}\left(R_{4}\right)\right] \\
& +2 X_{n}(r)-\left(\frac{r}{R_{4}}\right)^{n} X_{n}\left(R_{4}\right)-\left(\frac{r}{R_{3}}\right)^{n} X_{n}\left(R_{3}\right)
\end{aligned}
$$

and

$$
X_{n}(r)= \begin{cases}-\frac{\mu_{0} J_{n} r^{2}}{16}(4 \ln (\mathrm{r})-1) & \text { if } \mathrm{n}=2 \\ -\frac{\mu_{0} J_{n} r^{2}}{16} & \text { if } \mathrm{n}=\text { ip , } \mathrm{i}=1,3,5 \ldots \\ 0 & \text { otherwhere }\end{cases}
$$

Where $n$ is a positive integer, $\mathrm{p}$ is the number of pole-pairs and $E_{n}\left(r, R_{4}\right)$ is defined by (6).

The coefficients $A_{n}^{I I I}, B_{n}^{I I I}, C_{n}^{I I I}$ and $D_{n}^{I I I}$ are determined using a Fourier series expansions of $A_{I I}\left(R_{3}, \theta\right)$ and $A_{I V}\left(R_{4}, \theta\right)$ over the air-gap interval $[0,2 \pi]$.

$$
\begin{gathered}
A_{n}^{I I I}=\frac{2}{2 \pi} \int_{0}^{2 \pi} A_{I I}\left(R_{3}, \theta\right) \cos (n \theta) d \theta \\
B_{n}^{I I I}=\frac{2}{2 \pi} \int_{0}^{2 \pi} A_{I V}\left(R_{4}, \theta\right) \cos (n \theta) d \theta \\
C_{n}^{I I I}=\frac{2}{2 \pi} \int_{0}^{2 \pi} A_{I I}\left(R_{3}, \theta\right) \sin (n \theta) d \theta \\
D_{n}^{I I I}=\frac{2}{2 \pi} \int_{0}^{2 \pi} A_{I V}\left(R_{4}, \theta\right) \sin (n \theta) d \theta
\end{gathered}
$$

E. General Solution of Laplace's equation in the outer cryostat wall sub-domain (region IV)

The equation to solve is

$\frac{\partial^{2} A_{I V}}{\partial r^{2}}+\frac{1}{r} \frac{\partial A_{I V}}{\partial r}+\frac{1}{r^{2}} \frac{\partial^{2} A_{I V}}{\partial \theta^{2}}=0$ for $\left\{\begin{array}{l}R_{4} \leq r \leq R_{5} \\ 0 \leq \theta \leq 2 \pi\end{array}\right.$

According to the boundary conditions (16) and (17), the general solution of the magnetic vector potential in the outer cryostat wall sub-domain can be written as

$$
\begin{aligned}
& A_{I V}(r, \theta)= \\
& +\sum_{n=1}^{\infty}\left(A_{n}^{I V} \frac{R_{4}}{n} \frac{P_{n}\left(r, R_{5}\right)}{\mathrm{E}_{n}\left(R_{4}, R_{5}\right)} \cos (n \theta)+B_{n}^{I V} \frac{R_{4}}{n} \frac{P_{n}\left(r, R_{5}\right)}{\mathrm{E}_{n}\left(R_{4}, R_{5}\right)} \sin (n \theta)\right)
\end{aligned}
$$

Where $n$ is a positive integer, $P_{n}\left(r, R_{5}\right)$ and $E_{n}\left(R_{4}, R_{5}\right)$ are defined by (5) and (6). The coefficients $A_{n}^{I V}$ and $B_{n}^{I V}$ are determined using a Fourier series expansions of $\left.\frac{\partial A_{I I I}}{\partial r}\right|_{\mathrm{r}=\mathrm{R}_{4}}$ over the air-gap interval $[0,2 \pi]$. 


$$
\begin{aligned}
& A_{n}^{I V}=\left.\frac{2}{2 \pi} \int_{0}^{2 \pi} \frac{\partial A_{I I I}}{\partial r}\right|_{r=R_{4}} \cos (n \theta) d \theta \\
& B_{n}^{I V}=\left.\frac{2}{2 \pi} \int_{0}^{2 \pi} \frac{\partial A_{I I I}}{\partial r}\right|_{r=R_{4}} \sin (n \theta) d \theta
\end{aligned}
$$

\section{F. Electromagnetic torque}

The electromagnetic torque is obtained using the Maxwell stress tensor. A circle of radius $R_{e}$ in the air-gap is taken as the integration path so the electromagnetic torque is expressed as follows

$T_{e}=\frac{L R_{e}^{2}}{\mu_{0}} \int_{0}^{2 \pi} B_{I I r}\left(R_{e}, \theta\right) B_{I I \theta}\left(R_{e}, \theta\right) d \theta$

where $B_{I I r}=\frac{1}{r} \frac{\partial A_{I I}}{\partial \theta}$ and $B_{I I \theta}=-\frac{\partial A_{I I}}{\partial r}$ are respectively the radial and tangential flux densities in the air gap and $L$ is the active axial length of the FCSMC.

Using the coefficients of the magnetic field solution (35) in the air gap (region II), the electromagnetic torque expression (52) can be rewritten as

$$
T_{e}=\frac{\pi L R_{e}^{2}}{\mu_{0}} \sum_{n=1}^{\infty}\left(W_{n} X_{n}+Y_{n} Z_{n}\right)
$$

where

$$
\begin{gathered}
W_{n}=-A_{n}^{I I} \frac{R_{2}}{R_{e}} \frac{\mathrm{P}_{n}\left(R_{e}, R_{3}\right)}{\mathrm{E}_{n}\left(R_{2}, R_{3}\right)}-B_{n}^{I I} \frac{R_{3}}{R_{e}} \frac{\mathrm{P}_{n}\left(R_{e}, R_{2}\right)}{\mathrm{E}_{n}\left(R_{3}, R_{2}\right)} \\
X_{n}=-C_{n} \frac{R_{2}}{R_{e}} \frac{\mathrm{E}_{n}\left(R_{e}, R_{3}\right)}{\mathrm{E}_{n}\left(R_{2}, R_{3}\right)}-D_{n}^{I I} \frac{R_{3}}{R_{e}} \frac{\mathrm{E}_{n}\left(R_{e}, R_{2}\right)}{\mathrm{E}_{n}\left(R_{3}, R_{2}\right)} \\
Y_{n}=C_{n}^{I I} \frac{R_{2}}{R_{e}} \frac{\mathrm{P}_{n}\left(R_{e}, R_{3}\right)}{\mathrm{E}_{n}\left(R_{2}, R_{3}\right)}+D_{n}^{I I} \frac{R_{3}}{R_{e}} \frac{\mathrm{P}_{n}\left(R_{e}, R_{2}\right)}{\mathrm{E}_{n}\left(R_{3}, R_{2}\right)} \\
Z_{n}=-A_{n}^{I I} \frac{R_{2}}{R_{e}} \frac{\mathrm{E}_{n}\left(R_{e}, R_{3}\right)}{\mathrm{E}_{n}\left(R_{2}, R_{3}\right)}-B_{n}^{I I} \frac{R_{3}}{R_{e}} \frac{\mathrm{E}_{n}\left(R_{e}, R_{2}\right)}{\mathrm{E}_{n}\left(R_{3}, R_{2}\right)}
\end{gathered}
$$

\section{V.VALIDATION OF THE ANALYTICAL MODEL}

In order to validate the proposed model and for the geometrical parameters given in Table I, the analytical results have been compared with 2-D finite-element simulations obtained using FEM software [11]. The chosen parameters lead to non-saturated iron parts of the coupling so the linearity assumptions adopted for the analytical model are fulfilled.

Fig. 6 shows the magnetic flux lines under no-load $\left(\varphi=0^{\circ}\right)$ and load $\left(\varphi=57^{\circ}\right)$ conditions. The flux lines at no-load are symmetrical but it's not anymore the case under load conditions.
The waveforms of the flux density distribution (radial and tangential components) in the middle of the air-gap are presented in Fig. 7 and Fig. 8. It can be seen that the radial and tangential flux density waveforms under load conditions are deformed when compared to the no-load situation.

The static torque as well as the reluctance torque vs. the load angle $\varphi$ are presented in Fig.9. Notice that the reluctance torque has been computed by turning off the PMs, viz. $\mathrm{B}_{\mathrm{r}}=0$.

For the considered geometrical parameters, the pull-out torque is obtained for a load angle nearly equals to $\varphi=57^{\circ}$.

\begin{tabular}{|c|c|c|c|}
\hline & Symbol & Q Quantity & Value \\
\hline & $\overline{\mathrm{p}}$ & Number of pole pairs & 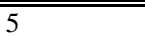 \\
\hline & $\mathrm{R}_{5}$ & Outer radius of SC coupling & $500 \mathrm{~mm}$ \\
\hline & $\mathrm{L}$ & Active axial length & $1000 \mathrm{~mm}$ \\
\hline & $\mathrm{N}$ & $\begin{array}{l}\text { Number of harmonics used } \\
\text { for magnetic field calculation } \\
\text { in the shaft, air-gap, winding } \\
\text { and outer cryostat domains }\end{array}$ & 20 \\
\hline & $\mathrm{K}$ & $\begin{array}{l}\text { Number of harmonics used } \\
\text { for magnetic field calculation } \\
\text { in the PM domain }\end{array}$ & 30 \\
\hline \multirow{6}{*}{$\begin{array}{l}\text { HTS } \\
\text { outer } \\
\text { rotor }\end{array}$} & $\mathrm{R}_{4}$ & Outer radius of HTS windings & $490 \mathrm{~mm}$ \\
\hline & $\mathrm{R}_{3}$ & Inner radius of HTS windings & $481 \mathrm{~mm}$ \\
\hline & $\alpha_{w}$ & $\begin{array}{l}\text { HTS coil width to half pole pitch } \\
\text { ratio }\end{array}$ & 0.1 \\
\hline & $\mathrm{N}_{\text {turns }}$ & Number of series turns & 104 \\
\hline & $\mathrm{I}_{\text {ccoil }}$ & Current of HTS coil & $100 \mathrm{~A}$ \\
\hline & $\mathrm{L}_{\mathrm{BSCCO}}$ & Total length of BSCCO tape & $2 \mathrm{~km}$ \\
\hline \multirow{4}{*}{$\begin{array}{l}\text { PM } \\
\text { inner } \\
\text { rotor }\end{array}$} & $\mathrm{R}_{2}$ & Outer radius of PM rotor & $461 \mathrm{~mm}$ \\
\hline & $\mathrm{R}_{1}$ & Inner radius of $\mathrm{PM}$ rotor & $276 \mathrm{~mm}$ \\
\hline & $\beta$ & Opening of PM & $0.35 \pi / \mathrm{p} \mathrm{rad}$ \\
\hline & $\mathrm{B}_{\mathrm{r}}$ & Remanence of the PM (NdFeB) & $1 \mathrm{~T}$ \\
\hline
\end{tabular}
The reluctance torque represents approximately $10 \%$ of the total torque (Fig.9.b).

A very good agreement is noticed between the finite element predictions and the analytical results.

TABLE I

GEOMETRICAL PARAMETERS OF FCSMC WITH SECTOR PMS

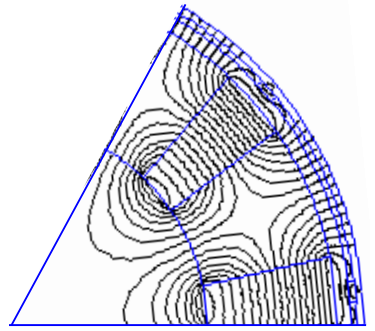

(a)

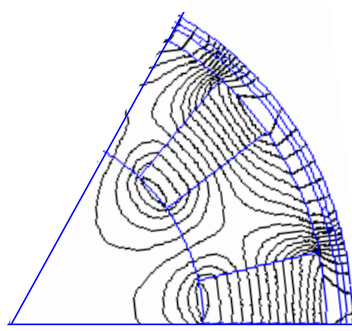

(b)
Fig. 6. Magnetic flux lines under (a) no-load $(\varphi=0)$ and (b) load conditions $\left(\varphi=60^{\circ}\right)$ 


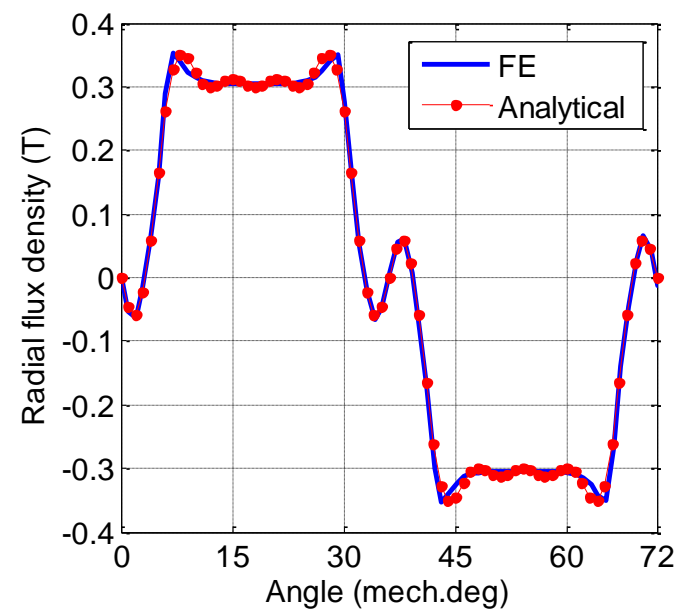

(a)

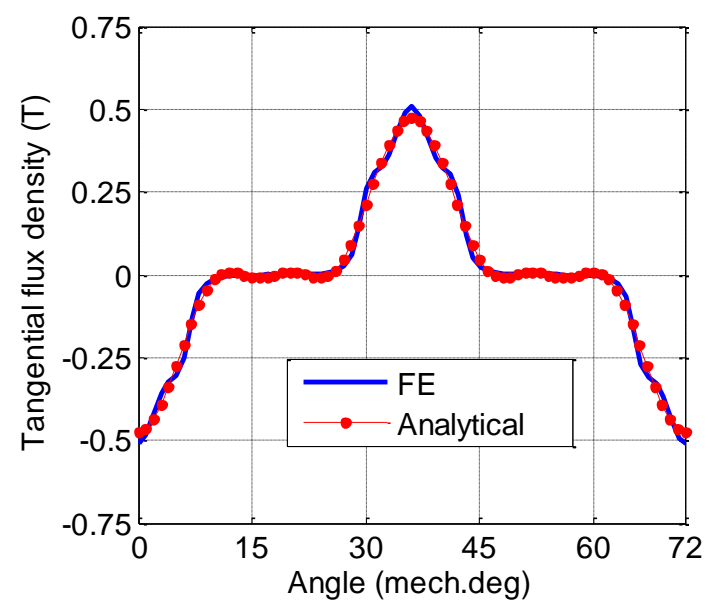

(b)

Fig. 7. Radial (a) and tangential (b) flux densities in the middle of the air gap $\left(\mathrm{R}_{\mathrm{e}}=345 \mathrm{~mm}\right)$ under no-load conditions $(\varphi=0)$

\section{THE HTS WINDING}

This section is devoted to the analysis of the HTS winding properties. It is well known that HTS materials exhibit a non linear relation between the electric field $E$ and the current density $J$. This non-linearity is well described by the power law [12]

$$
E=E_{c}\left(\frac{J}{J_{c}}\right)^{n}
$$

Where $J_{c}$ is the critical current density and $\mathrm{n}$ the index value of the experimental $U(I)$ curve [13].

$E_{c}$ is the critical electric field corresponding to the critical current with the arbitrary criteria $E_{c}=10^{-4} \mathrm{~V} / \mathrm{m}$. $J$ is the current density in the coil.

$J_{c}$ and $n$ depend on the cooling temperature, on the magnetic flux density components and on some mechanical constraints. So, the electric loadability (maximal allowable current avoiding thermal limits) also depends on the same physical properties.

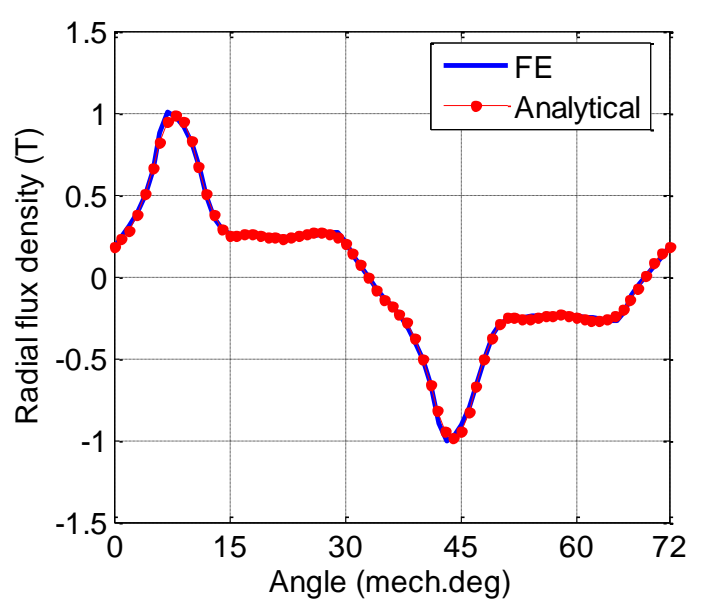

(a)

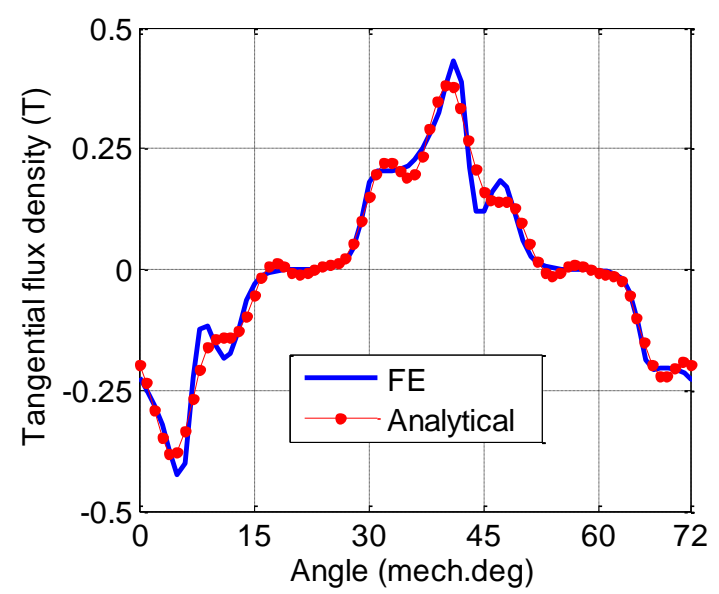

(b)

Fig. 8. Radial (a) and tangential (b) flux densities in the middle of the air gap $\left(\mathrm{R}_{\mathrm{e}}=345 \mathrm{~mm}\right)$ under load conditions $\left(\varphi=60^{\circ}\right)$

At a given operating temperature of the HTS material, the critical current density only depends on the electromagnetic and mechanical constraints. Nevertheless, one has to care about local hot-spot temperatures in the HTS winding. In fact, important local loss densities (due to a non-homogeneous cooling or a failure of the cooling system) can cause the quench of the HTS winding [14], [15].

Obviously, these thermal issues are of great importance but they are beyond the scope of the present paper so they will not be discussed further.

\section{A. Influence of the flux density distribution on the electric loadability of the HTS winding}

For the considered device, the HTS winding consists of $2 p$ race-track coils made from BSCCO tapes (Fig. 10). Each coil consists of $N_{\text {turns }}$ connected in series. The critical current of the coil is defined as the current flowing in the coil which causes a coil's terminal voltage equals to its critical value.

Since a 2D electromagnetic model is considered here, we neglect in this study the influence of the end-winding on the coil's voltage. So we only take into account the active length of the coupler. 


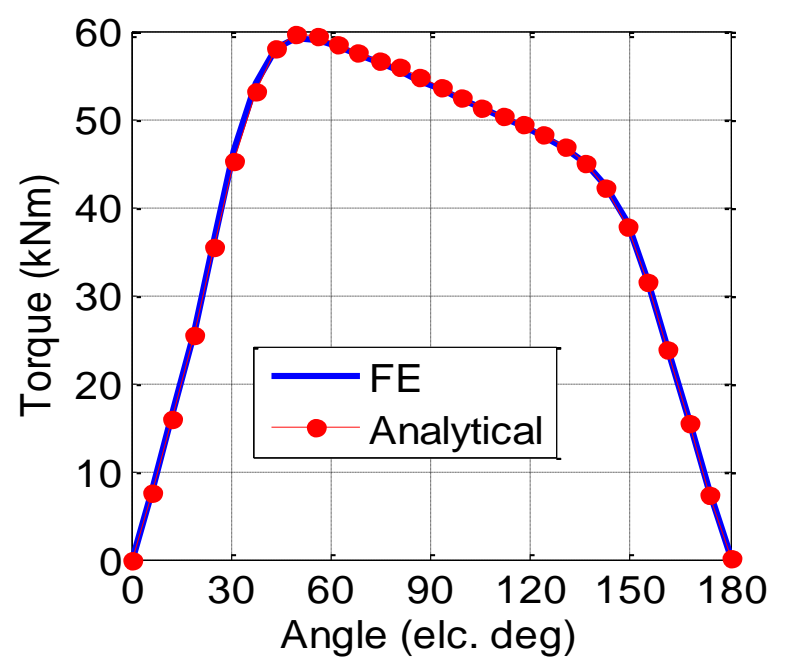

(a)

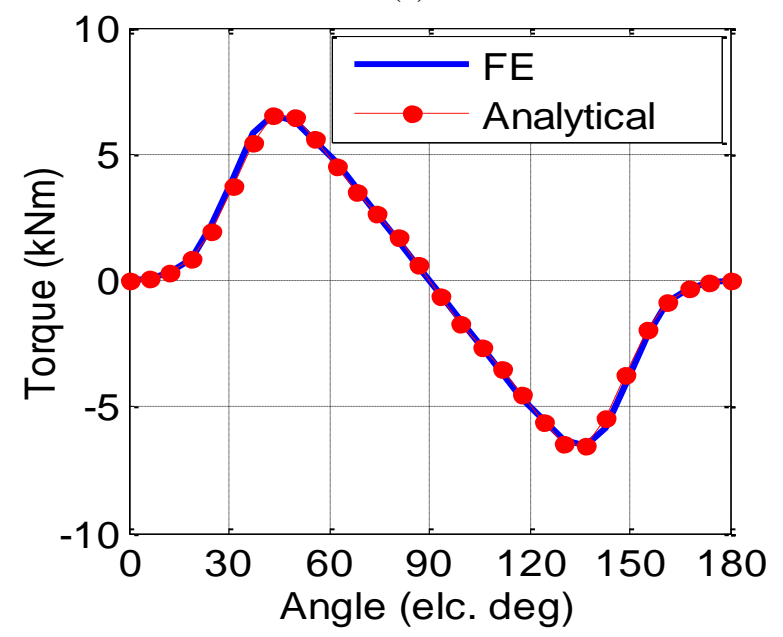

(b)

Fig. 9. Total static torque (a) and reluctance torque (b) of FCSMC

To describe the dependence of Jc and $n$ values on the flux density components, the Kim model is used [16]

$$
\begin{aligned}
& J_{c}(B)=\frac{J_{c 0}}{\left(1+\frac{\sqrt{k^{2} B_{/ /}^{2}+B_{\perp}^{2}}}{B_{0}}\right)^{\beta}} \\
& n(B)=\frac{n_{0}}{1+\frac{\left|B_{\perp}\right|}{B_{n 0}}}
\end{aligned}
$$

Where $J_{c 0}, \mathrm{n}_{0}$ and $\mathrm{k}$ are respectively the critical current density in zero field, the $\mathrm{n}$ value in zero field of the SC tape and the anisotropy factor $(<1)$.

$\mathrm{B}_{0}, \mathrm{~B}_{\mathrm{n} 0}$ and $\beta$ are positive constants characterizing the material at the given cooling temperature.

$B_{\perp}$ and $B_{\|}$are the values of the component of the flux density perpendicular and parallel to the largest surface of the tape (Fig. 10).

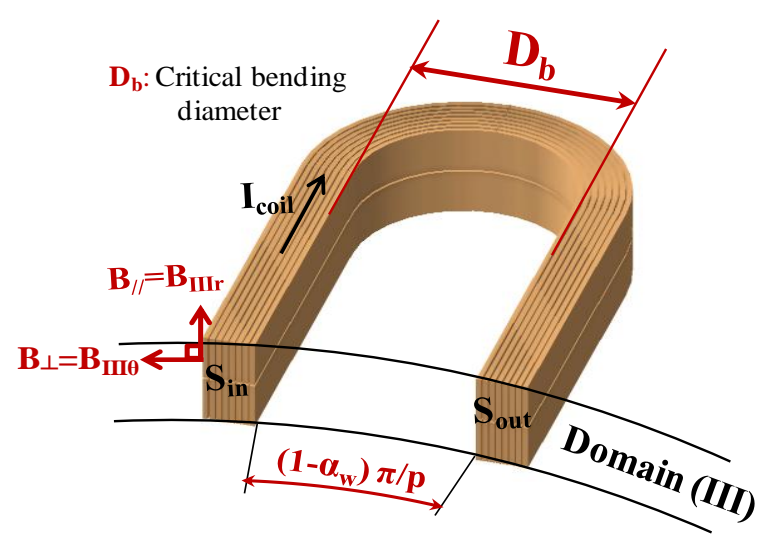

Fig. 10. 3D view part of a race-track BSCCO coil showing the tapes geometrical arrangement

Equations (59) and (60) show that the $J_{c}$ and $n$ values are mainly affected by the perpendicular flux density.

To rigorously determine the voltage over the coil's terminals, the actual stranded topology of the winding cross section has to be considered. The total voltage of the coil is then the sum of the elementary voltages corresponding to each turn of the HTS winding. This strict computation is not feasible using the developed analytical model and becomes very complicated by FE analysis since the generated mesh growth rapidly when the number of turns increases.

To overcome the problem, we use a bulk topology of the coil for which we define an average current density (as in (3)) given by

$$
J=\frac{N_{\text {turns }} I_{\text {coil }}}{S_{\text {coil }}}
$$

where $I_{\text {coil }}$ is the current flowing in each conductor and $S_{\text {coil }}$ is the cross section area of the coil.

This approach has been successfully used in our lab [17] since measured $U_{\text {coil }}\left(I_{\text {coil }}\right)$ characteristics are consistent with those computed using the bulk approximation.

In polar coordinates, the voltage across the coil is the sum of the voltages of the "in" and "out" of the plane bundles of conductors.

$$
U_{\text {coil }}=\frac{L N_{\text {turns }}}{S_{\text {coil }}}\left(\iint_{S_{\text {in }}} E_{\text {in }}(r, \theta) r d \mathrm{r} d \theta-\iint_{S_{\text {out }}} E_{\text {out }}(r, \theta) r d \mathrm{r} d \theta\right)
$$

Where $E_{\text {in }}(r, \theta)$ and $E_{\text {out }}(r, \theta)$ are respectively the electric fields over the cross sections of the coil $\left(\mathrm{S}_{\text {in }}\right)$ and $\left(\mathrm{S}_{\text {out }}\right)$. The double integral in (62) is calculated numerically.

By using the power law (58) associated to the Kim model (59) and (60), equation (62) becomes 


$$
U_{\text {coil }}=\frac{2 p \mathrm{LE}_{\mathrm{c}} N_{\text {utrrs }}}{\alpha_{w} \pi\left(R_{4}^{2}-R_{3}^{2}\right)}\left(\begin{array}{l}
\iint_{S_{\text {in }}}\left(\frac{J}{J_{c}\left(B_{\| /}, B_{\perp}\right)}\right)^{n(B)} r d r d \theta \\
+\iint_{S_{\text {out }}}\left(\frac{J}{J_{c}\left(B_{\|}, B_{\perp}\right)}\right)^{n(B)} r d r d \theta
\end{array}\right)
$$

For the studied device and using the analytical model, the parallel and perpendicular flux densities are respectively $B_{\|=} B_{I I I r}$ and $B_{\perp}=B_{I I I \theta}$ (Fig.10).

The critical voltage $U_{c}$ over the coil's terminals is

$$
U_{c}=2 N_{\text {turns }} L E_{c}
$$

\section{B. Mechanical stress due to bending}

HTS materials properties are very sensitive to mechanical stresses like bending, torsion or shear $[18,19]$. In addition to their harmful effects on the mechanical integrity of HTS materials, these stresses irreversibly decrease the critical current density.

The heads of race track coils should not be too short as they are subjected to bending and torsion during their manufacture. A minimal bending diameter $D_{b}$ is then required which constitutes a geometrical constraint on the coil opening (Fig. 10). Hence, the HTS coil width to half pole pitch ratio $\left(\alpha_{w}\right)$ has to fulfill the following condition

$$
\alpha_{w}<1-p \frac{D_{b}}{\pi R_{3}}
$$

The race track coil being made from rectangular tapes of thickness $e_{w}$, the number of layers $N_{c t}$ in the tangential direction $\theta$ is limited to a maximal value of

$$
N_{c t}=K_{f} \frac{\alpha_{w} \pi}{2 p} \frac{R_{3}}{e_{w}}
$$

where $K_{f}$ is the filling factor (in the tangential direction) of the HTS coil.

\section{Critical current of the HTS coupling}

The studied coil is made of BSCCO tapes cooled at $30 \mathrm{~K}$. The electrical and geometrical characteristics of the BSCCO tape are given respectively on Tables II and III. These characteristics correspond to the last generation BSCCO tape (of type $\mathrm{H}$ for $\mathrm{dc}$ applications) manufactured by Sumitomo [20].

For $\mathrm{K}_{\mathrm{f}}=0.8$ at no-load $\left(\varphi=0^{\circ}\right)$, Fig.11 shows the coil's terminals voltage vs. the current. The critical voltage of one BSCCO coil is $U_{c}=21 \mathrm{mV}$. The critical current obtained for the studied HTS coupling is about 277A, which represents $52 \%$ of the self-field critical current of the used BSCCO tape $\left(\mathrm{I}_{\mathrm{c} 0}=531 \mathrm{~A}\right)$. The analytical predictions are in good agreement compared to the numerical computations.

Fig. 12 presents the critical current of the BSCCO coil for different load angles $\varphi$ of the superconducting rotor. It can be seen that the maximum value of the critical current is about $462 \mathrm{~A}\left(0.87 \mathrm{I}_{\mathrm{c} 0}\right)$ obtained for a load angle nearly equals to $\varphi=33^{\circ}$ (electrical angle). For the pull-out torque position corresponding to $\varphi=57^{\circ}$, the critical current is about $441 \mathrm{~A}$ $\left(0.83 \mathrm{I}_{\mathrm{c} 0}\right)$.

The minimum value of the critical current, obtained for $\varphi=0^{\circ}$, is about $277 \mathrm{~A}\left(0.52 \mathrm{I}_{\mathrm{c} 0}\right)$. This limit allows fixing the operating current of the coupler at a value lower than this minimal critical current in order to prevent thermal failures or

\begin{tabular}{|c|c|c|c|}
\hline Symbol & \multicolumn{2}{|c|}{ Quantity } & \\
\hline $\mathrm{e}_{\mathrm{w}}$ & \multicolumn{2}{|c|}{ BSCCO wire thickness } & \\
\hline $1_{\mathrm{w}}$ & \multicolumn{2}{|c|}{ BSCCO wire width } & \\
\hline $\mathrm{D}_{\mathrm{b}}$ & \multicolumn{2}{|c|}{ Bending diameter } & \\
\hline & \multicolumn{3}{|c|}{$\begin{array}{c}\text { TABLE III } \\
\text { PARAMETERS OF THE KIM MODEL } \\
\end{array}$} \\
\hline & \multicolumn{3}{|c|}{$\mathbf{J}_{\mathbf{c}}(\mathbf{B})$} \\
\hline & $\mathrm{J}_{\mathrm{c} 0}$ & \multicolumn{2}{|c|}{$537 \mathrm{~A} / \mathrm{mm}^{2}$} \\
\hline & $\mathrm{B}_{0}$ & \multicolumn{2}{|c|}{$1.01 \mathrm{~T}$} \\
\hline & $\beta$ & \multicolumn{2}{|c|}{0.87} \\
\hline & $\mathrm{k}$ & \multicolumn{2}{|c|}{0.182} \\
\hline & \multicolumn{3}{|c|}{$\begin{array}{l}\mathbf{n}(\mathbf{B}) \\
\end{array}$} \\
\hline & $\overline{\mathrm{n}_{0}}$ & \multicolumn{2}{|c|}{31} \\
\hline & $\mathrm{B}_{\mathrm{n} 0}$ & \multicolumn{2}{|c|}{$2 \mathrm{~T}$} \\
\hline
\end{tabular}
to allow some mechanical over-load.

TABLE II

GEOMETRICAL PARAMETERS OF THE BSCCO TAPE [20]

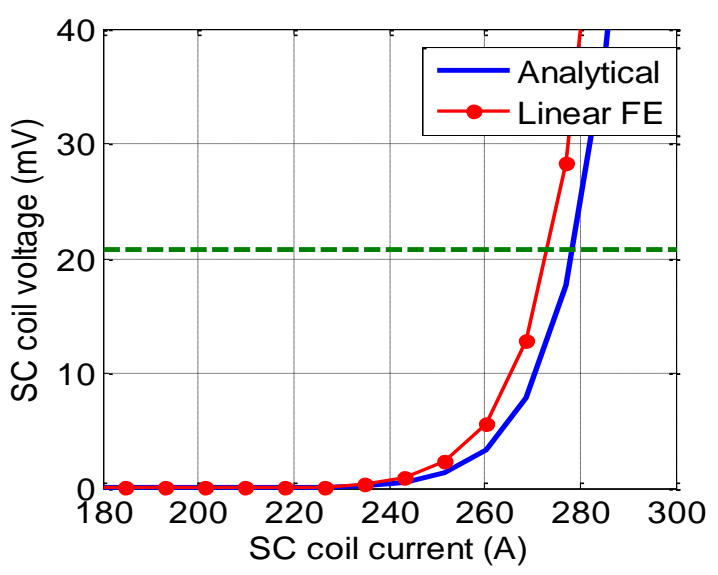

Fig. 11. Voltage vs. current of HTS coil of $\operatorname{FCSMC}\left(\varphi=0^{\circ}\right)$ 


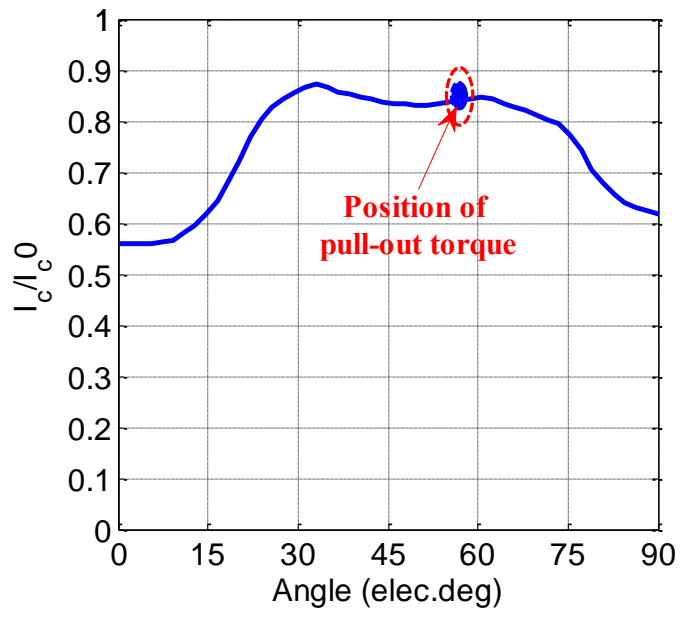

Fig. 12. Critical current $I_{d} / I_{c 0}$ vs. load angle of FCSMC $\left(I_{c 0}=531 A\right)$

\section{PERFORMANCES OF THE ANALYTICAL MODEL TO COMPUTE SATURATED FCSMC WITH RECTANGULAR PMS}

The rotor of flux concentration machines usually uses rectangular magnets rather than sector magnets which are practically difficult to magnetize.

So from now, the rotor of the studied coupler will be composed of rectangular magnets embedded in a ferromagnetic yoke. Indeed, we propose an analysis of the capability of the developed analytical model in predicting the performances of FCSMC with rectangular PMs.

Notice that superconductors create a strong magnetic field which saturates the iron parts, in particular in the inner rotor. The FE computations are then performed both in the linear and in the non-linear cases. The ferromagnetic material used in this study (US Steel Type 2-S) has a B(H) curve shown in Fig.13.

To allow the analytical computation, the rectangular magnets are replaced by sector ones having the same volume (Fig.14). The rectangular magnet opening at $r=R_{1}$, noted $\beta^{\prime}$, couldn't exceed $R_{1} \pi / p$. We define the ratio between $\mathrm{R}_{1}$ and $\mathrm{R}_{2}$ as

$$
\alpha_{r}=\frac{R_{1}}{R_{2}}
$$

The sector PM, having the same volume as the rectangular one, has to fulfill the following condition

$$
\alpha_{m}<\frac{4 p}{\pi} \frac{\alpha_{r}}{1+\alpha_{r}} \sin \left(\frac{\pi}{2 p}\right)
$$

For all what follows and in order to predict the performances of FCSMC with rectangular PMs, linear FE, non-linear FE and analytical computations are performed and compared.

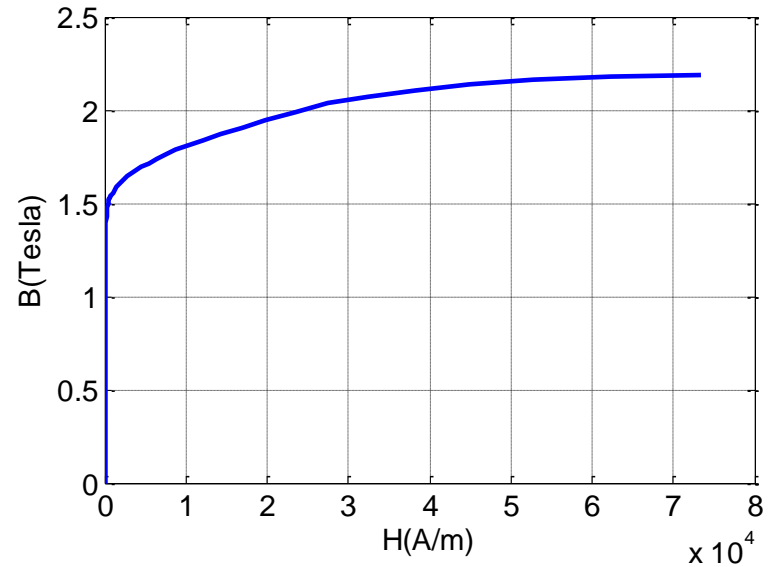

Fig. 13. $\mathrm{B}(\mathrm{H})$ curve of the ferromagnetic material

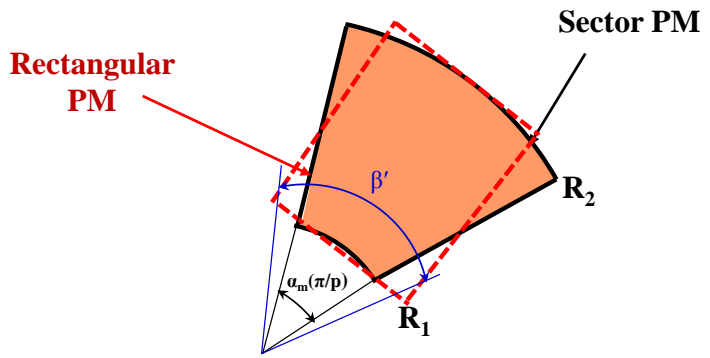

Fig.14. Replacing rectangular PMs by sector ones

The following values have been adopted: $\alpha_{r}=0.6$, $\alpha_{m}=0.35, \alpha_{w}=0.1$. These choices allow a reasonable saturation level in the iron parts.

Fig.15 presents the voltage-current curve of the HTS coil at no-load $\left(\varphi=0^{\circ}\right)$. The critical current obtained using the analytical model is about $277 \mathrm{~A}$; this value is very close to the one computed using the linear FE model. The non-linear FE computation gives a critical current of about $272 \mathrm{~A}$ which is $1.8 \%$ lower than the one given by the analytical model. These good predictions suggest that the critical current is mainly limited by the self field created by the HTS winding current. Indeed, for reasonable saturation levels, this current gives the same flux density distribution across the coil area whatever the geometrical configuration (rectangular or sector PMs).

Fig. 16 shows the flux lines under load conditions $\left(\varphi=57^{\circ}\right.$, $I_{\text {coil }}=80 \% I_{c}=222.4 \mathrm{~A}$ ). We notice some leakage flux in the shaft which mainly depends on the values of $\alpha_{\mathrm{r}}$ and $\alpha_{\mathrm{m}}$.

As shown in Fig.17, the air gap radial flux density harmonics are globally higher with the rectangular PMs configuration. For the most important harmonic orders $(1,3,5,7,9)$, the relative difference between the non-linear FE computations and the analytical predictions doesn't exceed $7 \%$. 
For a current value $I_{\text {coil }}=222.4 \mathrm{~A}$, Fig. 18 presents the static torque vs. load angle computed by the different methods in use. The linear FE prediction gives a pull-out torque of about $198 \mathrm{kNm}$ while the non-linear FE computation gives 195 $\mathrm{kNm}$. The analytical model underestimates the pull out torque since it predicts $171 \mathrm{kNm}$. Furthermore, the load angle corresponding to the pull out torques is $\varphi=55^{\circ}$ using the FE models whereas this angle is $13^{\circ}$ higher (viz. $\varphi=68^{\circ}$ ) when using the analytical model. One can also note that the torque computed analytically is lower than the FE one whatever the load angle.

Nevertheless, the analytical model allows a correct estimation of the pull-out torque.

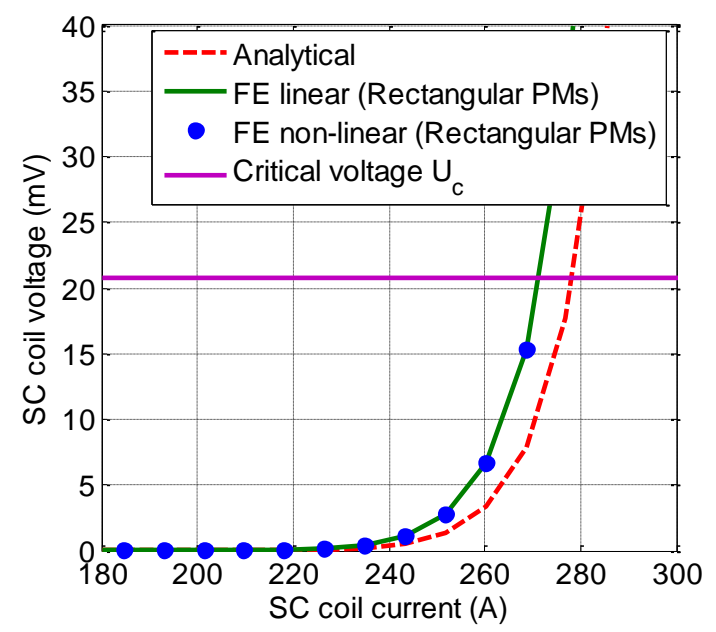

Fig. 15. Voltage vs. current curves of the BSCCO coil for $\varphi=0^{\circ}$

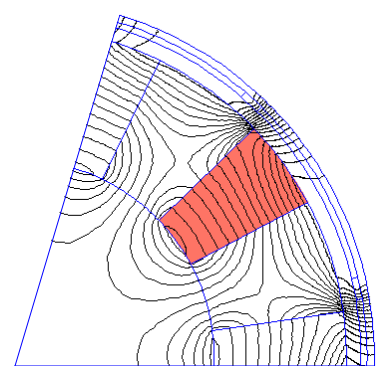

(a)

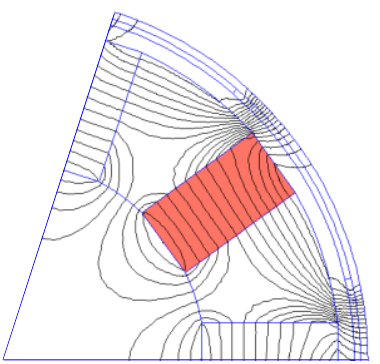

(b)
Fig. 16. Magnetic flux lines of FCSMC with (a) sector and (b) rectangular PMs under load conditions ( $\varphi=57^{\circ}$ élec, $\left.\mathrm{I}_{\text {coil }}=222.4 \mathrm{~A}\right)$.

\section{A. Influence of $p$ and $\alpha_{r}$ on the critical current and the torque capabilities of FCSMC}

By fixing $R_{2}=461 \mathrm{~mm}$ as in Table $\mathrm{I}$, the critical current computed for different values of the number of pole pairs $p$ and $\varphi=57^{\circ}$ is presented in Fig. 19. The other parameters remain unchanged; in particular $\alpha_{w}$ is constant so the overall volume of the HTS material is also constant whatever the value of $p$. It can be seen from Fig.20 that the FE models as well as the analytical model predict identical critical current values for $\mathrm{p}=2 \div 5$. Beyond, the analytical model overestimates the numerical one by about $9 \%$. Furthermore, one can see that the critical current increases with $p$. This is due to the fact that the local values of the magnetic flux density over the HTS coil decrease as p increases.

Regarding the influence of the ratio $\alpha_{r}$, the calculations showed that it has no influence on the critical current values.

For a current corresponding to $80 \%$ of $\mathrm{I}_{\mathrm{c}}$ in the HTS windings, Fig. 20 presents the variation of the pull-out torque vs. the number of pole pairs $p$ for 2 values of $\alpha_{r}$. It can be seen that the torque decreases monotonically as $p$ increases, and the analytical computations follow the same tendency as the nonlinear FE ones.

In order to analyze the influence of the parameter $\alpha_{r}$, Fig.21 shows the evolution of the pull-out torque when $\alpha_{r}$ varies between 0.2 and 0.8 . It is clear that an optimal value of $\alpha_{r}$ witch maximizes the torque exists. This value is about $\alpha_{r}=0.55(170 \mathrm{kNm})$ for $p=4$ and $\alpha_{r}=0.7(130 \mathrm{kNm})$ for $p=8$.

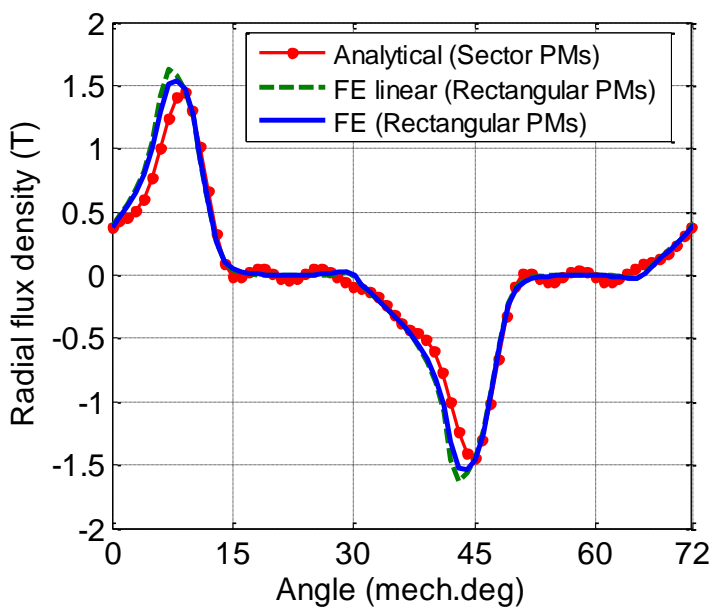

(a)

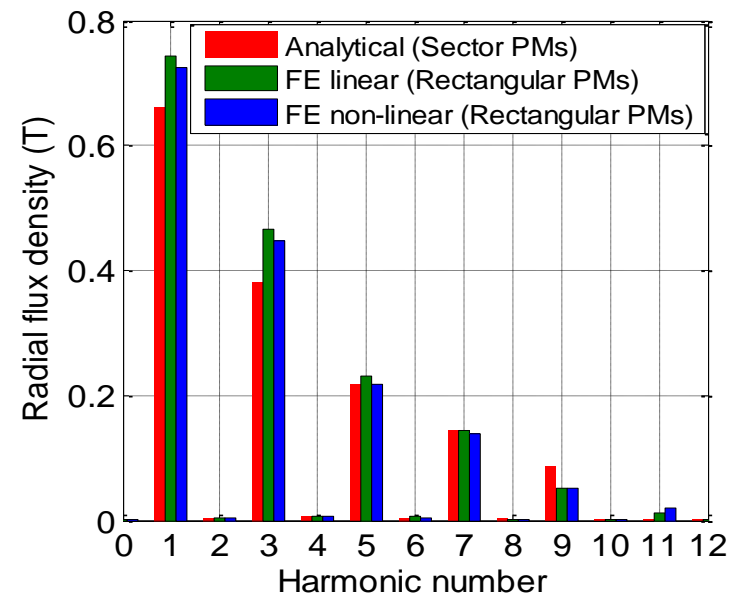

(b)

Fig. 17. Radial flux density waveforms (a) and their harmonic spectra (b) at load conditions $\left(\varphi=57^{\circ}\right.$ elect, $\left.I_{\text {coil }}=222.4 \mathrm{~A}\right)$. 


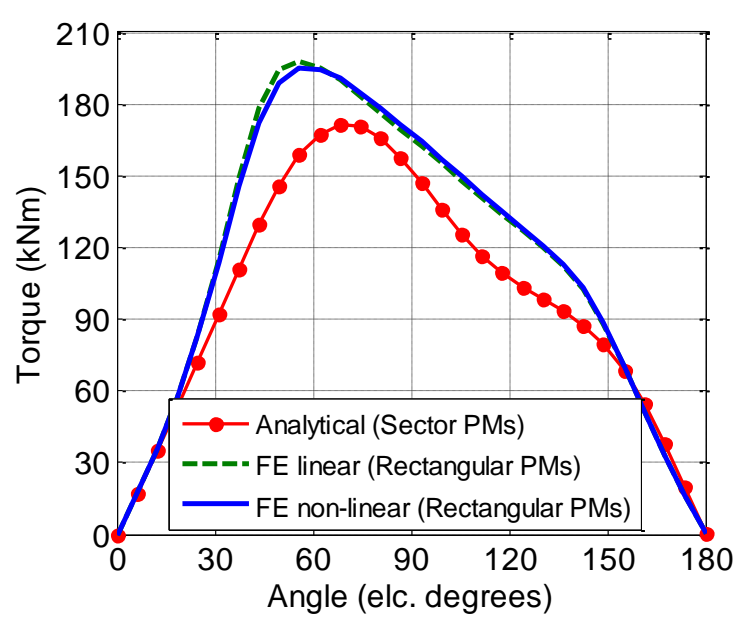

Fig. 18. Static torque obtained by different methods in use for $\mathrm{I}_{\text {coil }}=222.4 \mathrm{~A}$

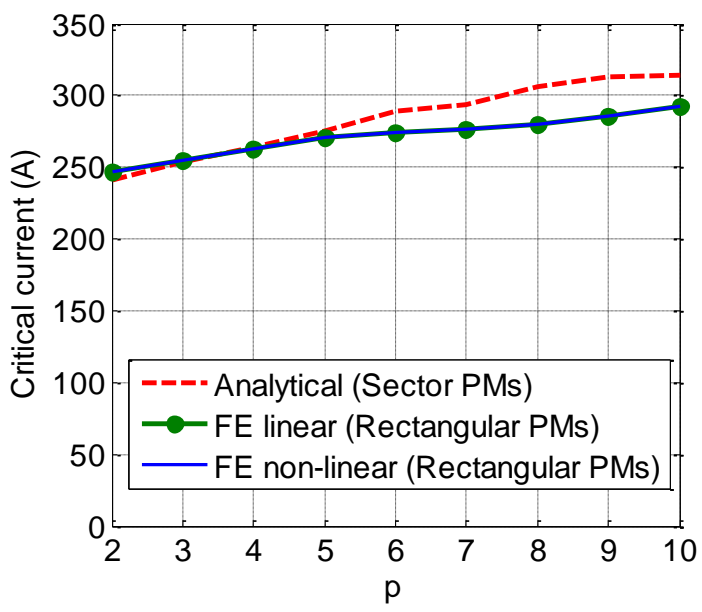

Fig. 19. Critical current versus the number of pole pairs $\left(\alpha_{\mathrm{r}}=0.6\right)$

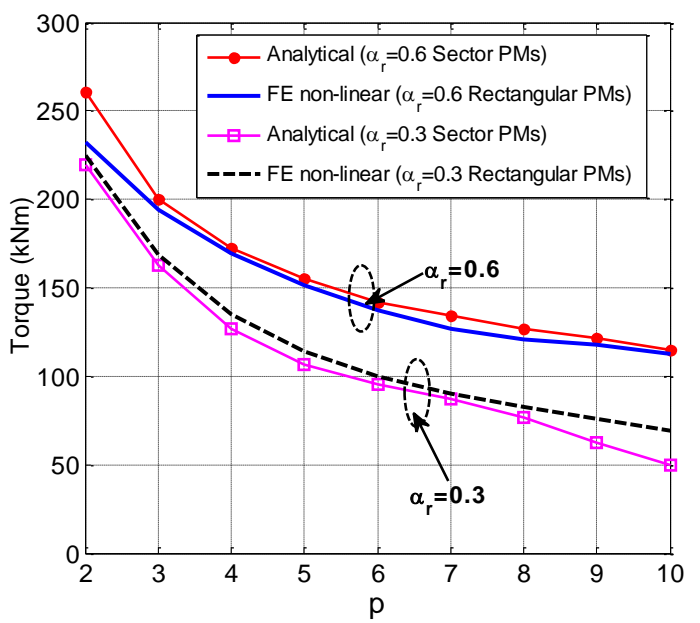

Fig. 20. Pull-out torque vs. the number of pole-pairs for $\alpha_{\mathrm{r}}=0.3$ and $\alpha_{\mathrm{r}}=0.6$

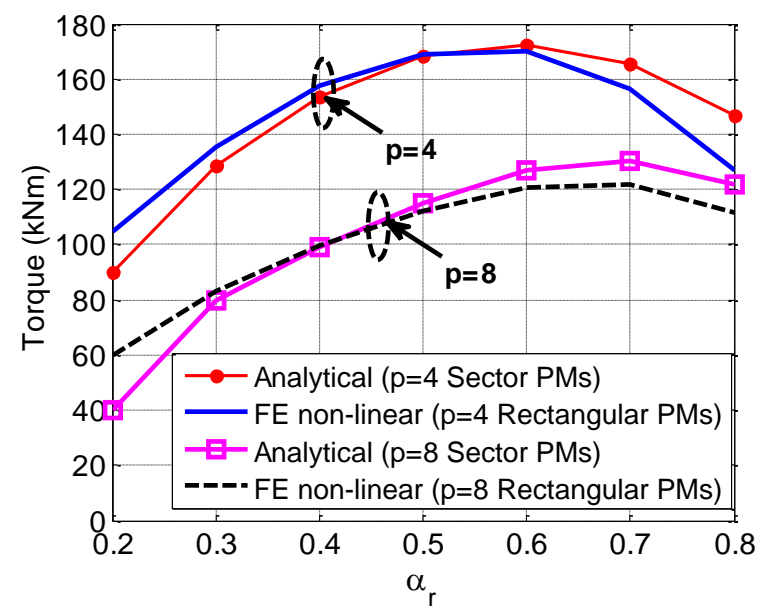

Fig. 21. Pull-out torque versus the ratio $\alpha_{\mathrm{r}}$ for $\mathrm{p}=4$ and $\mathrm{p}=8$.

\section{B. Optimized torque transmission capabilities of the FCSMC}

The parametric studies showed that optimal configurations in terms of torque transmission and electric loadabilty of the HTS winding exist. These studies have been conducted with a moderate active length of HTS tape. To increase the torque produced by the coupler, we need to use more HTS material as to increase the airgap magnetic field. By doing so, one can face some problems related to the magnets demagnetization. Hence, we have to ensure that the used $\mathrm{NdFeB}$ magnets are not demagnetized by systematically checking the values of the tangential magnetic field (which corresponds to the direction of the magnetization).

Several simulation studies (analytical and numerical) allowed us to obtain an optimized FCSMC whose main dimensions are presented in Table IV. The minimal value of the critical current is obtained at $\varphi=0^{\circ}\left(\mathrm{I}_{\mathrm{c}}=305 \mathrm{~A}\right)$.

The static torque curve, obtained for a HTS coil current $\mathrm{I}_{\text {coil }}=0.8 \mathrm{I}_{\mathrm{c}}=243 \mathrm{~A}$, is presented in Fig. 22 . The pull-out torque reaches $425 \mathrm{kNm}$. A $5 \mathrm{~cm}$ back-iron thickness is enough to close the flux which leads to an active torque density of about $450 \mathrm{kNm} / \mathrm{m}^{3}$.

As an example, this coupler is able to transmit the torque of a 5 MW-120 rpm ship propulsion motor. It has clearly the potential to be used in high power application systems like wind turbines, marine propulsion...

\section{VIII.CONCLUSION}

The paper presents a new type of torque transmitter which can replace favorably, by avoiding any material contact, a mechanical torque tube usually used in superconducting machines. The use of high critical current BSCCO tapes at $30 \mathrm{~K}$ and flux concentration PMs rotor allows to obtain a high torque density magnetic coupler.

An exact 2-dimensional analytical method to calculate the magnetic field distribution in FCSMC with sector magnets has 
been proposed and validated through FE computations. The study takes into account the electrical and mechanical constraints of BSCCO tape at $30 \mathrm{~K}$. The results presented in this paper have shown that the developed model is able to predict the critical current of the BSCCO coil and the performances of the superconducting coupler with a good accuracy when compared to the FE predictions.

In the flux concentration machine the permanent magnets are usually rectangular, so we have been led to introduce an equivalent sector shape magnets in order to obtain analytically the results presented here. The different results showed that, by considering the HTS constraints, the analytical model developed in this paper predicts the value of the pull-out torque within a maximum error of about $20 \%$ when compared to the finite element calculations of the rectangular PM topology. Furthermore, different parametric studies have been performed. It has been shown that the analytical predictions follow the same tendency as the numerical ones in evaluating the electromagnetic torque and the critical current.

An optimized FCSMC has been also presented leading to a very important torque density coupler. Hence, it can be used in high power electromechanical systems.

TABLE IV

\begin{tabular}{|c|c|c|c|}
\hline \multicolumn{4}{|c|}{$\begin{array}{c}\text { TABLE IV } \\
\text { GEOMETRICAL PARAMETERS OF THE OPTIMIZED FCSMC }\end{array}$} \\
\hline & Symbol & "Quantity & Value \\
\hline & $\mathrm{p}$ & Number of pole pairs & 8 \\
\hline \multirow{6}{*}{$\begin{array}{l}\text { HTS } \\
\text { outer } \\
\text { rotor }\end{array}$} & $\mathrm{R}_{3}$ & Inner radius of HTS rotor & $\begin{array}{l}485.7 \\
\mathrm{~mm}\end{array}$ \\
\hline & $\mathrm{R}_{5}$ & Outer radius of FCSMC & $\begin{array}{l}500 \\
\mathrm{~mm}\end{array}$ \\
\hline & $\alpha_{\mathrm{w}}$ & $\begin{array}{l}\text { HTS coil width to half pole pitch } \\
\text { ratio }\end{array}$ & 0.43 \\
\hline & $\mathrm{N}_{\text {turns }}$ & Number of turns & 143 \\
\hline & $\mathrm{I}_{\mathrm{c}}$ & Critical current of HTS coil & $305 \mathrm{~A}$ \\
\hline & $\mathrm{L}_{\mathrm{BSCCO}}$ & $\begin{array}{l}\text { Total active length of BSCCO } \\
\text { tape }\end{array}$ & $\begin{array}{l}4.57 \\
\mathrm{~km}\end{array}$ \\
\hline \multirow{3}{*}{$\begin{array}{l}\text { PM } \\
\text { inner } \\
\text { rotor }\end{array}$} & $\mathrm{R}_{2}$ & Outer radius of PM rotor & $\begin{array}{l}465.7 \\
\mathrm{~mm}\end{array}$ \\
\hline & $\mathrm{R}_{1}$ & Inner radius of PM rotor & $\begin{array}{l}248 \\
\mathrm{~mm}\end{array}$ \\
\hline & $\beta^{\prime}$ & Opening of rectangular $\mathrm{PM}$ at $\mathrm{R}_{1}$ & $\begin{array}{l}0.46 \\
\pi / \mathrm{p} \mathrm{rad}\end{array}$ \\
\hline
\end{tabular}

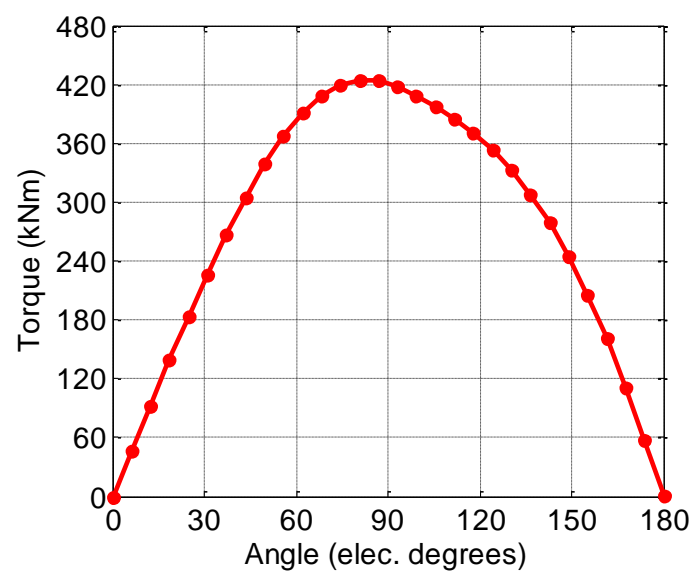

Fig. 22. Static torque of the optimized FCSMC computed with nonlinear FE (Icoil=243 A)

\section{REFERENCES}

[1] M. Cong, T. Li, "Design and Application of Magnetic Coupling Used for Ultra-high Vacuum Robot", 15th International conference on Mechatronics and Machine Vision in Practice (M2VIP 08), pp.346-351, 2-4 Dec 2008, Auckland, New-Zealand.

[2] L. Jian, K. T. Chau, W. Li, Jiangui Li, " A Novel Coaxial Magnetic Gear Using Bulk HTS for Industrial Applications," IEEE Trans. Appl. Supercond, vol. 20, no. 3, pp 981-984, 2010.

[3] M. Okano, K. Tsurumoto, S. Togo, N. Tamada, and S. Fuchino, "Characteristics of the magnetic gear using a bulk high-Tc superconductor," IEEE Trans. Appl. Supercond, vol. 12, no. 1, pp. 979-983, Mar. 2002.

[4] M. Enokizono, T. Todaka, Y. Tsuchida, A. Ikariga, S. Urata, T. Mauchi, A. Umeduki, K. Ebihara, H. Shioduki, H. Shimoji, Y. Gotho, M. Obata, Y. Kido, "Development of high density and high efficiency machines," Journal of Materials Processing Technology, Vol.181, No.1-3, pp.110-114, 2007.

[5] L. J. Wu, Z. Q. Zhu, D. Staton, M. Popescu, and D. Hawkins, "Comparison of Analytical Models for Predicting Cogging Torque in Surface-Mounted PM Machines," Proc. ICEM, Rome, 6 p., 2010.

[6] Z. J. Liu and J. T. Li, "Analytical solution of air-gap field in permanent magnet motors taking into account the effect of pole transition over slots," IEEE Trans. Magn., vol. 43, no. 10, pp. 3872-3882, Oct. 2007.

[7] Z. Q. Zhu, L. J. Wu, and Z. P. Xia, "An accurate subdomain model for magnetic field computation in slotted surface-mounted permanent magnet machines," IEEE Trans. Magn., vol. 46, no. 4, pp. 1100-1115, Apr. 2010.

[8] Q. Gu and H. Gao, "Effect of slotting in PM electrical machines," Elect. Mach. Power Syst., vol. 10, pp. 273284, 1985.

[9] T. Lubin, S. Mezani, and A. Rezzoug, "Exact analytical method for magnetic field computation in the air-gap of cylindrical electrical machines considering slotting effects, " IEEE Trans. Magn., vol. 46, no. 4, pp. 10921099, Apr. 2010.

[10] B. L. J. Gysen, E. Ilhan, K. J. Meessen, J. J. H. Paulides, and E. A. Lomonova, "Modeling of Flux Switching Permanent Magnet Machines with Fourier Analysis," IEEE Trans. Magn., vol. 46, no. 6, pp. 1499-1502, Jun. 2010.

[11]D. C. Meeker, Finite Element Method Magnetics Version 4.2 (1 October 2011 Build) http://www.femm.info.

[12] P. Bruzzone, "The index $\mathrm{n}$ of the voltage-current curve, in the characterization and specification of technical superconductors," Physica C, Superconductivity, vol. 401, no. 1-4, p. 7-14, Jan. 2004.

[13]Z. Zhang, X. Du, Y. Zhou, X. Yang, Z. Xu, Z. Zhu, J. Zhang, X. Li, G. Zhang, and L. Xiao, "Investigations on N Values of Long Bi2223/Ag Tapes, " IEEE Trans. Appl., , vol. 20, no. 3, pp. 1585 - 1588, 2010.

[14] J. Lee, Y. Kwon, S. Baik, E. Lee, Y. Kim, T. Moon, H. Park, W. Kwon, J. Hong, M. Park, I. Yu, and Y. Jo, "Thermal Quench in HTS Double Pancake Race Track 
Coil," IEEE Trans. Appl., Supercond, vol. 17, no.2, pp. 1603-1606, Jun. 2007.

[15]B. Shoykhet, and S. Umans, "Quench in HighTemperature Superconducting Motor Field Coils: Computer Simulations and Comparison With Experiments," IEEE Trans. Appl., Supercond, vol. 17, no. 2, pp. 1623-1628, Jun. 2007.

[16] Y. Kim, C. Hempstead, and A. Strnad, "Critical persistent currents in hard superconductors," Physical Review Letters, vol. 9, no. 7, pp. 306-309, 1962.

[17]S. Bendali, Dimensionnement d'un moteur supraconducteur HTc (in french), PHD thesis, University of Lorraine, France, December 2012.

[18] M. Oomen, M. Leghissa, N. Proelss, and H. W. Neumueller,"Transposed-Cable Coil \& Saddle Coils of HTS for Rotating Machines: Test Results at $30 \mathrm{~K}$," IEEE Trans. Appl., Supercond, vol. 19, no.3, pp. 1633-1638, Jun. 2009.

[19] C. Barth, K. P. Weiss, and W. Goldacker, "Influence of Shear Stress on Current Carrying Capabilities of High Temperature Superconductor Tapes," IEEE Trans. Appl., Supercond, vol. 21, no.3, pp. 3098-3101, Jun. 2011.

[20] Sumitomo Electric, http://global-sei.com/super/hts_eltype_h.html

Lamia Belguerras was born in Algiers, Algeria, in 1979. She received the Dipl.-Ing. and the Magister degrees from the University of Sciences and Technology Houari Boumediene (USTHB), Algiers, Algeria, in 2005 and 2008, respectively. She is currently a Ph.D. student at GREEN Laboratory, University of Lorraine, Nancy, France. Her research interests include the modelling and optimization of electrical machines and superconducting magnetic couplings.

Larbi Hadjout was born in Bordj-Menaïel, Algeria, in 1967. $\mathrm{He}$ received the Dipl.-Ing., the Magister and the PhD degrees from Ecole Nationale Polytechnique, Algiers, Algeria in 1991, 1994 and 2006, respectively. He is currently a Senior Lecturer at "Laboratoire des Systèmes Electriques et Industriels", USTHB, Algiers, Algeria where his research interests include the modelling and design of electrical machines.
Smail Mezani was born in Algiers, Algeria, in 1974. He received the Dipl.Ing. and Magister degrees from the University of Sciences and Technology Houari Boumediene, Algiers, in 1996 and 1999, respectively, and the Ph.D. degree from the Institut National Polytechnique de Lorraine, Nancy, France, in 2004. He is a Lecturer of Electrical Engineering with the Faculty of Sciences and Technology, University of Lorraine. His researches are undertaken in GREEN Laboratory and deal with numerical and analytical modelling of electrical machines and contactless torque transmissions, coupled magnetic and thermal problems, and the applications of superconductors in electromechanical devices.

Thierry Lubin was born in Sedan, France, in 1970. He received the M.S. degree from the University of Paris 6, France in 1994 and the Ph.D. degree from the University Henri Poincaré, Nancy, France, in 2003.

$\mathrm{He}$ is currently an associate professor of Electrical Engineering at the University of Lorraine, France, at the Groupe de Recherche en Electrotechnique et Electronique de Nancy (GREEN). His interests include analytical modeling of electromechanical devices and applied superconductivity in electrical engineering.

Abderrezak Rezzoug received the electrical engineer degree from ENSEM INPL, Nancy, France in 1972, and the Dr. Ing. diploma and the Ph.D. degree from INPL, in 1979 and 1987 respectively.

After working at the INPL as an assistant Professor until 1991, he had a career as a professor and is currently a Professor emeritus of University of Lorraine, France. As a member of the Groupe de Recherche en Electrotechnique et Electronique de Nancy, his main subjects of research concern superconducting applications to electrical device and electrical machines. 